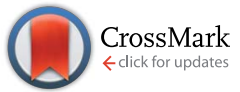

Cite this: RSC Adv., 2017, 7, 8973

Received 20th December 2016 Accepted 24th January 2017

DOI: $10.1039 / c 6 r a 28475 b$

rsc.li/rsc-advances

\section{Synthesis, characterization and photovoltaic studies of oligo(acriflavine) via chemical oxidative polymerization}

\author{
Feyza Kolcu*ab and İsmet Kaya*a
}

The present work reports a simple and inexpensive way for the synthesis of a novel water-soluble conjugated oligo(acriflavine) (OAC). Oligo(acriflavine) was synthesized via chemical oxidative polycondensation by $\mathrm{H}_{2} \mathrm{O}_{2}(30 \%)$ as the oxidant at an optimum reaction temperature of $110{ }^{\circ} \mathrm{C}$ without use of an additional external template. The chemical structure of the synthesized compound was confirmed by FT-IR, UV-Vis, ${ }^{1} \mathrm{H}-\mathrm{NMR}$ and ${ }^{13} \mathrm{C}-\mathrm{NMR}$ techniques. Further characterization was employed using, photophysical, electrochemical, photovoltaic thermogravimetric-differential thermal analysis (TGDTA), fluorescence (PL), cyclic voltammetry $(\mathrm{CV})$ and differential scanning calorimetry (DSC) measurements. The number average molecular weight of the oligomer was found to be $4950 \mathrm{Da}$ with a polydispersity index of 1.18. Photoluminescence (PL) properties of the synthesized materials were determined in solution form. The solvent effect on the optical properties of OAC was studied in selected solvents. The spectral analysis displayed a bicolor emission behavior when OAC solution was irradiated at different wavelengths. The HOMO-LUMO energy levels and electrochemical $\left(E_{g}^{\prime}\right)$ band gap values of OAC were determined by CV measurement. Optical and electrochemical band gaps of OAC with more conjugated structure were lower than for AC. XRD analysis signified that the oligomer was in a semicrystalline form. To further study the morphologic properties of the OAC, Scanning Electron Microscopy (SEM) images were illustrated at different amplifications. It was demonstrated that the structure of OAC was essentially a ladder oligomer with phenazine rings. The best performing photovoltaic cell, based on $\mathrm{OAC}$ reached a $\mathrm{J}_{\mathrm{sc}}$ of $0.14 \mathrm{~mA} \mathrm{~cm}^{-2}$, a $V_{\mathrm{oc}}$ of $0.37 \mathrm{~V}$, and a $\mathrm{FF}$ of 0.50 , giving a power conversion efficiency $(\% \eta)$ of $0.027 \%$ under AM 1.5 irradiation $\left(100 \mathrm{~mW} \mathrm{~cm}^{-2}\right)$.

\section{Introduction}

Conducting polymers have been recently investigated for the production of technological applications. ${ }^{1-4}$ The area of applications encloses the production of biosensors, ${ }^{5}$ chemical gas sensors, ${ }^{6}$ electrochromic displays, ${ }^{7,8}$ photovoltaic and optical devices, ${ }^{9}$ light-emitting diodes and field effect transistors. ${ }^{\mathbf{1 0 - 1 3}}$ Materials with a delocalized $\pi$-electron system absorb sunlight and transport charge carriers. This is now true of materials within the field of inherently conducting polymers like polyconjugated polymers using chemical oxidation polymerization. Interest in controlling electroactive organic materials, such as conducting polymers has recently grown. Solar cell applications triggered the search for the incorporation of semiconductors into dye-synthesized solar cells. To construct dye-sensitized solar cells, coumarine- ${ }^{\mathbf{1 4 , 1 5}}$ indoline- ${ }^{\mathbf{1 6 , 1 7}}$

${ }^{a}$ Çanakkale Onsekiz Mart University, Department of Chemistry, Polymer Synthesis and Analysis Laboratory, 17020, Çanakkale, Turkey. E-mail: feyzakolcu@comu.edu.tr; kayaismet@hotmail.com; Fax: +90 2862180533

${ }^{b}$ Çanakkale Onsekiz Mart University, Lapseki Vocational School, Department of Chemistry and Chemical Processing Technologies, Çanakkale, Turkey cyanine $^{\mathbf{1 8}}$ - and hemicyanine $\mathrm{e}^{\mathbf{1 9 2 0}}$ - based dyes have recently been employed in photovoltaic applications.

Water-alcohol soluble conjugated polymers have attracted considerable attention owing to their important applications in polymer solar cells as cathode interlayers and in PLEDs, organic photovoltaics, polymer cells as well as in drug delivery and detection of biomacromolecules. ${ }^{21-25}$ Oxidative polymerization (OP) commonly used is one of the suitable techniques to prepare conjugated conductive polymers. Using OP, the solubility problem of a conductive polymer can be overcome using amino-functionalized conjugated polymers that are soluble in alcohol in the presence of trace acetic acid due to weak interaction between the nitrogen atom of amino group and acetic acid. $^{26}$

On the other hand, highly crystalline conjugated polymers are very important for efficient charge carrier transport, and a crystalline structure of the polymers will effectively enhance performance of their electronic or optical devices. ${ }^{27}$ Several crystalline conjugated polymers have been synthesized using chemical routes. ${ }^{28-30}$ Photovoltaic (PV) devices emerge as an attractive way of converting energy directly from the sunlight. Among all types of photovoltaic devices, polymer-based organic 
solar cells (OSCs) are particularly intriguing since they have the advantages of low production cost, processing at room temperature, mechanical flexibility, and suitability for mass production in addition to being relatively quiet, not producing toxic substances or greenhouse gases, and requiring little maintenance during operations. ${ }^{31}$

Encouraged by these explanations in this article we report the synthesis and characterization of $\pi$-conjugated structure of acriflavine (AC) having phenazine units in its backbone. AC is a dye used as antiseptic agent, bactericidal inhibitory, genetically active agent and reagent for drug analyses. ${ }^{32-34}$

A novel water-soluble conjugated polymer is presented by containing same side-chains bearing primary amino $\left(-\mathrm{NH}_{2}\right)$ groups responsible for dissolving in aqueous solution. Chemical oxidative polymerization of aromatic diamine-AC where the nitrogen atoms of diamine group were the most susceptible site for the polymerization was simple and environmentally friendly. Polymer consists of purely head-to-tail or orthocoupled coupled acriflavine monomers by employing the direct chemical oxidation of acriflavine.

Based on the foregoing information, we aimed to develop the potential applications of this new polymer in various disciplines, due to the fluorescent probe properties and high emission quantum yields. UV-Vis, CV, TGA, DSC, and PL techniques were carried out to characterize the photo physical, electrochemical and thermal properties of the new system. The electronic properties were analyzed using UV-Vis absorption spectrophotometer, fluorescence emission spectroscopy and cyclic voltammetry.

\section{Experimental}

\section{Materials}

Acriflavine (AC; 3,6-diamino-10-methylacridinium chloride) was purchased from Sigma-Aldrich Co. (USA). Methanol (MeOH), ethanol, acetic acid, chloroform $\left(\mathrm{CHCl}_{3}\right)$, tetrahydrofurane (THF), N,N-dimethylformamide (DMF), dimethyl sulfoxide (DMSO), toluene, acetonitrile, $30 \%$ aqueous solution of hydrogen peroxide $\left(\mathrm{H}_{2} \mathrm{O}_{2}\right)$ and all other solvents used were supplied by Merck Chemical Co. (Germany), and used as received without any purification.

\section{The synthesis of oligo-acriflavine (OAC)}

Acriflavine (AC) $(0.01 \mathrm{~mol}, 2.59 \mathrm{~g})$ dissolved in $40 \mathrm{~mL}$ of methanol was polymerized in $250 \mathrm{~mL}$ two-necked round bottom flask connected to a condenser by adding 3 drops of acetic acid and a solution of $1 \mathrm{~mL}$ of $\mathrm{H}_{2} \mathrm{O}_{2}$ dropwise within $30 \mathrm{~min}$, respectively. The reaction was refluxed for 2 days at $105^{\circ} \mathrm{C}$. Then, the reaction mixture was cooled to room temperature to get the oxidative oligomer (OAC) of acriflavine. The black color precipitate was filtered and the unreacted monomer was removed by washing with ethanol $(3 \times 25 \mathrm{~mL})$. The black product was then kept overnight in an oven at $60{ }^{\circ} \mathrm{C}$ for drying (yield 69\%). Scheme 1 outlined the general synthetic route of OAC.

For AC. FT-IR $\left(\mathrm{cm}^{-1}\right)$ : 3300-3169 $\nu(\mathrm{N}-\mathrm{H}), 3028 \nu(\mathrm{C}-\mathrm{H}$, phenyl), $2844 \nu(\mathrm{C}-\mathrm{H}$, aliphatic $), 1622 \nu(\mathrm{C}=\mathrm{N}$, aromatic ring $)$,
$1594 \nu\left(\mathrm{C}=\mathrm{C}\right.$ phenyl), $1326 \nu(\mathrm{C}-\mathrm{N}) .{ }^{1} \mathrm{H}$ NMR $\left(\right.$ DMSO-d $\left._{6}\right): \delta_{\mathrm{H}} \mathrm{ppm}$, 8.69 (d, 1H, Hd), 7.81 (d, 1H, Hb), 7.76 (d, 1H, Ha), 7.45 (s, 1H, $\mathrm{Hc}$ ), 6.97 (d, 1H, He), 6.91 (d, 1H, Hf), 6.85 (s, 1H, Hg), 7.27, 6.76 $\left(\mathrm{s}, 4 \mathrm{H}, 2 \mathrm{NH}_{2}\right), 3.90\left(\mathrm{~s}, 3 \mathrm{H}, \mathrm{CH}_{3}\right) .{ }^{13} \mathrm{C} \mathrm{NMR}\left(\mathrm{DMSO}_{6}\right): \delta \mathrm{ppm}$, 157.88 (C1), 156.60 (C9), 144.09 (C11), 143.2 (C12), 142.93 (C5), 134.09 (C3), 132.18 (C7), 118.26 (C4), 117.2 (C6), 116.92 (C13), 116.89 (C10), 94.8 (C2), 94.03 (C8), 23.1 (C14).

For OAC. FT-IR $\left(\mathrm{cm}^{-1}\right): 3154 \nu(\mathrm{N}-\mathrm{H}), 3034 \nu(\mathrm{C}-\mathrm{H}$, phenyl), $2905 \nu(\mathrm{C}-\mathrm{H}$, aliphatic $), 1660 \nu(\mathrm{C}=\mathrm{N}$, aromatic ring $), 1596 \nu(\mathrm{C}=$ C phenyl). ${ }^{1} \mathrm{H}$ NMR (DMSO- $\left.\mathrm{d}_{6}\right): \delta_{\mathrm{H}} \mathrm{ppm}, 11.20(\mathrm{~s}, 2 \mathrm{H}$, aromatic $\mathrm{N}-\mathrm{H}$ ), 9.56 (s, 2H, Hd), 7.83 (d, 2H, Hb), 7.38 (s, 2H, Hc), 7.36 (s, 2H, He), 6.31 (d, 2H, Hb), 6.29 (d, 2H, Ha), 5.99 (s, 2H, Hg), 3.34 $\left(\mathrm{s}, 3 \mathrm{H}, \mathrm{CH}_{3}\right.$ ). ${ }^{13} \mathrm{C}$ NMR (DMSO-d ${ }_{6}$ ): $\delta \mathrm{ppm}, 169.12$ (C1), 166.55 (C9), 165.72 (C2), 163.18 (C8), 159.17 (terminal C1), 158.55 (terminal C9), 149.42 (C11), 144.94 (C12), 142.48 (C5), 139.96 (C3), 138.86 (C7), 128.94 (C4, C6), 124.71 (C10, C13), 120.49 (terminal C2), 117.42 (terminal C8), 23.1 (C14).

\section{Characterization techniques}

The solubility tests were applied to OAC (1 mg) in different solvents $(1 \mathrm{~mL})$ at room temperature. The infrared (FT-IR) spectra were recorded using a Perkin Elmer FT-IR Spectrum One with the universal ATR sampling attachment (4000-650 $\mathrm{cm}^{-1}$ ) to study the chemical structures of AC and OAC. ${ }^{1} \mathrm{H}$ and ${ }^{13} \mathrm{C}-\mathrm{NMR}$ spectra were recorded by using Bruker Avance DPX (USA) operating at the range of 400 and $100.6 \mathrm{MHz}$, respectively. The samples were dissolved in deuterated DMSO, and tetramethylsilane (TMS) was used as an internal standard at $25{ }^{\circ} \mathrm{C}$. Thermogravimetric and Differential Thermal Analyses (TGDTA) were carried out between $20-1000{ }^{\circ} \mathrm{C}$ using Perkin Elmer Diamond Thermal Analysis System. TG-DTA analyses were carried out at heating rate of $10{ }^{\circ} \mathrm{C} \mathrm{min}^{-1}$ in a platinum crucible under nitrogen atmosphere $\left(100 \mathrm{~mL} \mathrm{~min}{ }^{-1}\right)$. Perkin Elmer Sapphire Differential Scanning Calorimetry was placed in a covered aluminum pan with a $15 \mathrm{mg}$ of the synthesized oligomer for DSC experiment between 25 and $420{ }^{\circ} \mathrm{C}$ (in $\mathrm{N}_{2}$, rate $\left.10{ }^{\circ} \mathrm{C} \min ^{-1}\right)$. The number average molecular weight $\left(M_{\mathrm{n}}\right)$, weight average molecular weight $\left(M_{\mathrm{w}}\right)$ and polydispersity index (PDI) of OAC were determined by Gel Permeation Chromatography-Light Scattering (GPC-LS) device by Malvern Viscotek GPC Dual 270 max. For GPC investigations a medium $300 \times 8.00 \mathrm{~mm}$ Dual column addition $1 \mathrm{~g} \mathrm{~L}^{-1}$ of lithium bromide in DMF ( $1 \mathrm{~mL} \mathrm{~min}^{-1}$ ) was used as solvent. A Light Scattering Detector (LS) and a refractive index detector (RID) were used to analyze the products at $55{ }^{\circ} \mathrm{C}$. X-ray diffraction (XRD) measurements were recorded by a PANalytical empyrean model X-ray diffractometer instrument (The Netherlands) with $\mathrm{CuK}_{\alpha}$ radiation at a wavelength of $1.54 \AA$ over a range of $2 \theta$ from $5^{\circ}$ to $90^{\circ}$ with a scanning rate of $4^{\circ} \mathrm{min}^{-1}$.

\section{Optical properties}

In order to investigate the optical properties of AC and OAC, the optical band gaps $\left(E_{\mathrm{g}}\right)$ recorded in Ultraviolet-visible (UV-vis) spectra (UK) were calculated from their absorption edges. Using Analytikjena Specord 210 Plus, the absorption spectra of the $\mathrm{AC}$ and $\mathrm{OAC}$ were recorded in selected solvents like DMF, 


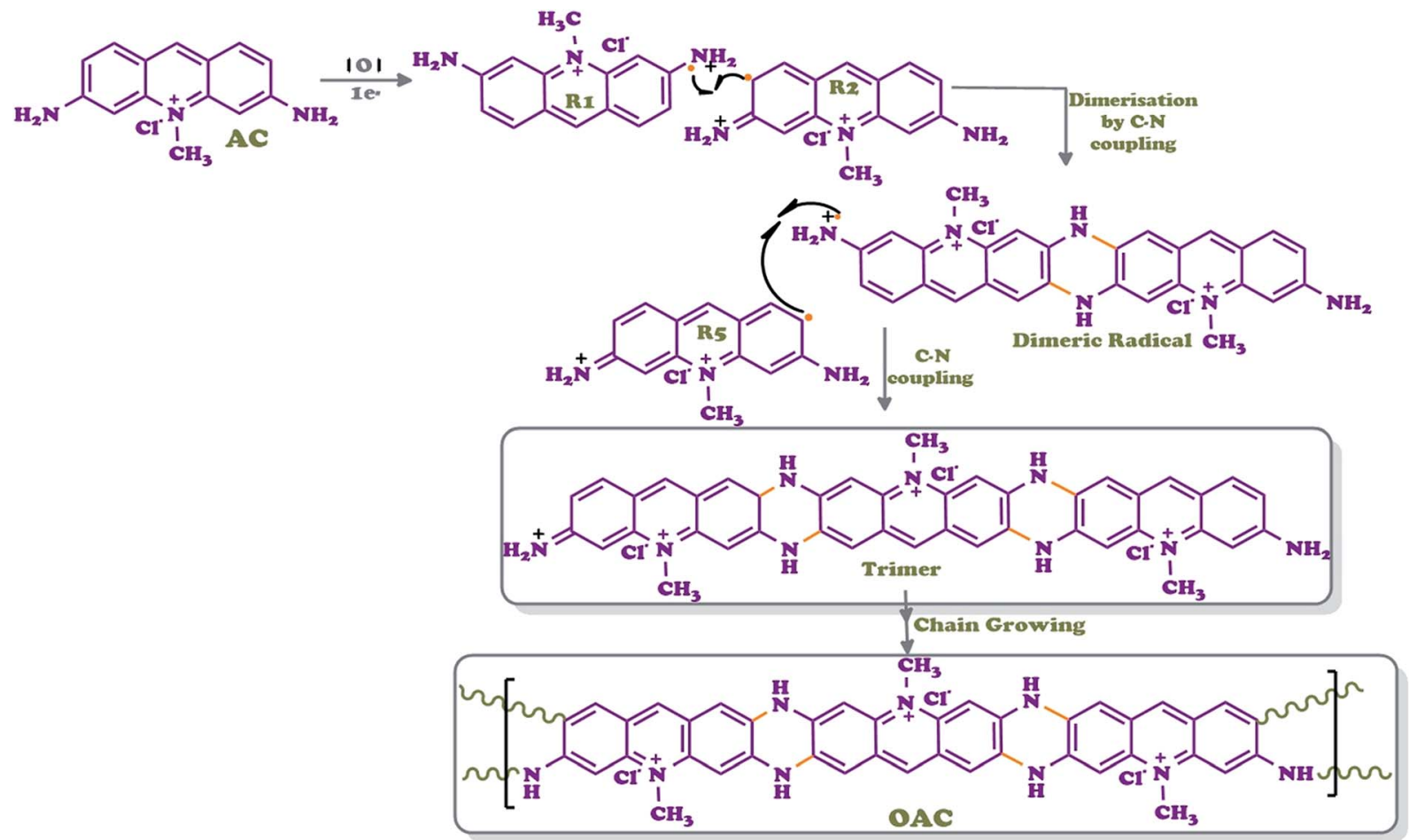

Scheme 1 Synthetic pathway of OAC.

DMSO, MeOH and water at $25{ }^{\circ} \mathrm{C}$. The emission and excitation spectra were obtained by using a Shimadzu RF-5301PC spectrofluorophotometer (Japan) in different solvents including DMF, DMSO, methanol and water with $0.1 \mathrm{~g} \mathrm{~L}^{-1}$ as solution concentrations for all measurements. Photoluminescence (PL) spectra were obtained with a slit width of $3 \mathrm{~nm}$. Fluorescence quantum yields (QYs) were determined using the comparative method as described in the literature. ${ }^{35,36}$ Fluorescein solution in $0.1 \mathrm{M}$ of aqueous $\mathrm{NaOH}$ was used as a standard.

\section{Electrochemical properties}

Cyclic voltammetry (CV) measurements were performed with a CHI 660C Electrochemical Analyzer (Texas, USA) at a potential scan rate of $25 \mathrm{mV} \mathrm{s}^{-1}$ to investigate electrochemical properties of AC and OAC. All the experiments were carried out in a dry box filled with argon atmosphere at room temperature. Silver wire as a reference electrode, glassy carbon electrode (GCE; $d=$ $0.3 \mathrm{~cm}$ in diameter) as a working electrode and platinum wire as a counter electrode were used for all the measurements. The electrochemical potential of $\mathrm{Ag}$ was calibrated with respect to the ferrocene/ferrocenium $\left(\mathrm{Fc} / \mathrm{Fc}^{+}\right)$couple. The half-wave potentials $\left(E^{1 / 2}\right)$ of $\left(\mathrm{Fc} / \mathrm{Fc}^{+}\right)$in $0.1 \mathrm{M}$ tetrabutylammoniumhexafluorophosphate $\left(\mathrm{TBAPF}_{6}\right) /$ acetonitrile solution are $0.39 \mathrm{~V}$ and $0.38 \mathrm{~V} v s$. $\mathrm{Ag}$ wire and supporting calomel electrolyte, respectively. The voltammetric measurements were carried out in acetonitrile for $\mathrm{AC}$ and $\mathrm{DMSO} /$ acetonitrile mixture, respectively. The electrochemical HOMO and LUMO energy levels and band gaps $\left(E_{g}^{\prime}\right)$ of OAC were calculated from the oxidation and reduction onset values. ${ }^{37}$

\section{The photovoltaic characteristic of oligomer}

The photovoltaic characteristics were studied by the illuminationdependent current-voltage measurements. Current-voltage characteristic of a solar cell gives information about maximum power point (MPP). ${ }^{38}$ The dye-sensitized solar cell was prepared using commercial Solaronix test cell kit (Solaronix 74992). $\mathrm{TiO}_{2}$ electrode was immersed into a $1 \mathrm{mM}$ DMSO solution of OAC for 24 hours. Then, the dye layer was washed with ethanol and let to dry at room temperature. Subsequently, this electrode was clamped together with a Pt electrode (Solaronix) and applied Solaronix-AN50 electrolyte solution onto the interface between the two plates. The photocurrent-voltage characteristics of the prepared cell as a function of light intensity were monitored using MTI-BST8-STAT-EIS-LD, Single Channel Potentiostat/Galvanostat with Electrochemical Impedance Spectroscopy (USA) and under AM1.5 standard condition.

\section{Morphological and electrical properties}

Scanning electron microscopy (SEM) photographs of oligomer were recorded using a JEOL JSM 7100F instrument (Japan) to observe morphology of oligomer particles. The oligomer solution was sprayed on an aluminum surface using a custom built electrospinning setup, which consisted of a $2.5 \mathrm{~mL}$ syringe containing the oligomer solution driven out of using an NE-300 single syringe pump (Pump Systems Inc., USA). A metal 25gauge syringe needle tip and collecting plate were connected to a high voltage power supply (model 73030P, Genvolt Ltd., UK). The applied voltage was set at $7 \mathrm{kV}$ and kept constant for all experiments. A flow rate of $1 \mathrm{~mL} \mathrm{~h}^{-1}$ was used in order to create a stable system. 
Solid state electrical conductivity of OAC in the form of a pellet was measured by four-point probe technique at room temperature and atmospheric pressure using Keithley 2400 Electrometer instrument. The oligomer was pressed in a hydraulic pressure developing up to $1687.2 \mathrm{~kg} \mathrm{~cm}^{-2}$ to prepare a pellet form.

\section{Results and discussion}

\section{Synthesis and characterization of OAC}

The oxidative polymerization of orange-colored acriflavine with $\mathrm{H}_{2} \mathrm{O}_{2}$ in methanol yielded an oligomer, OAC, as shown in Scheme 1. OAC was isolated as black-colored powder form with yield of $69 \%$. This fact is an indication that the coupling of acriflavine molecules to chains took place. OAC was completely soluble in highly aprotic polar solvents, DMSO, DMF and THF in spite of partly solubility in some polar solvents, such as $\mathrm{H}_{2} \mathrm{O}$ and ethanol. While the polarity of the solvent was reduced, like dichloromethane, hexane and heptane, OAC became insoluble.

Eight main coupling modes for the polymerization of acriflavine (AC) were identified and given in Scheme 2. The most probable coupling sites for the polymerization were through the radical formed as $\mathrm{R} 1$ and $\mathrm{R} 2$. $\mathrm{AC}$ was unit structure linked to each other via the $\mathrm{C}-\mathrm{N}=\mathrm{C}$ or $\mathrm{C}-\mathrm{NH}-\mathrm{C}$ bonds. In such a way that two acridine units could be regarded as forming one pyrazine ring as result of an intramolecular cyclization reaction, leading to the ladder-like structure.

Therefore, R1 and R2 radicals could favor the formation of pyrazine ring during the polymerization via $\mathrm{C}-\mathrm{N}$ coupled dimer (Scheme 1). The formation of a cycle reduces the energy of the molecule owing to the generation of an aromatic structure. ${ }^{39}$ The ortho position was subsequently oxidized to form phenazine-like moieties along the backbone of the polymer. Phenazine cycles could further participate in the subsequent chain growth. In this way, a phenazine-containing oligomer is able to initiate the chain growth. The computational results suggest that intramolecular cyclization is thermodynamically favorable, leading to the formation of ladder segments during the course of oxidative polymerization of aromatic diamine polymer growth mechanism. ${ }^{40}$

FT-IR spectroscopy was used to confirm the chemical structure of AC and OAC. The peaks at 3300 and $3169 \mathrm{~cm}^{-1}$ attributed to the $\mathrm{N}-\mathrm{H}$ stretching vibration of the $-\mathrm{NH}_{2}$ groups were replaced by one broader band at $3154 \mathrm{~cm}^{-1}$ for OAC which signified the transformation of the primary amine to a secondary amine through polymerization that took place on nitrogen atoms of primary amine groups and resulted in forming the $\mathrm{C}-\mathrm{N}$ coupled structure. The absorption peak at $3028 \mathrm{~cm}^{-1}$ ascribable to the stretching modes of aromatic $\mathrm{C}-\mathrm{H}$ bond was observed at $3034 \mathrm{~cm}^{-1}$ in the oligomer structure of OAC. The peak bands at $2844 \mathrm{~cm}^{-1}$ and $2905 \mathrm{~cm}^{-1}$ were corresponded to the aliphatic methylene $\left(-\mathrm{CH}_{3}\right)$ of $\mathrm{AC}$ and $\mathrm{OAC}$, respectively. FT-IR spectrum of AC indicated two peaks at 1480 and $1377 \mathrm{~cm}^{-1}$ for the $\mathrm{C}-\mathrm{H}$ scissoring and methyl rock, respectively, became broader in that of OAC. Two sharp peaks at 1622 and $1594 \mathrm{~cm}^{-1}$ attributed to the $\mathrm{C}=\mathrm{N}$ and $\mathrm{C}=\mathrm{C}$ stretching vibration modes for $\mathrm{AC}$, became wider due to an increase in conjugation after polymerization and observed at 1660 and $1596 \mathrm{~cm}^{-1}$, respectively. The peaks at 1449 and $1510 \mathrm{~cm}^{-1}$ of OAC pointed to the ring stretching vibrations of newly formed pyrazine ring between two acridine units. The bending vibration of $\mathrm{C}-\mathrm{N}$ bond for AC was observed at $1326 \mathrm{~cm}^{-1}$. In other words, phenazine ring could be considered as a part of the oligomer chain. ${ }^{41,42}$

${ }^{1} \mathrm{H}$ NMR of AC was also recorded for a comparison to OAC for further enlightment of the synthesized structure and shown in Fig. 1 and 2. In the spectrum, the peaks in the aromatic region observed at 7.81 (doublet), 7.76 (doublet), 7.45 (singlet), 6.97 (doublet), 6.91 (doublet) and 6.85 (singlet) ppm were attributed to the $\mathrm{Hb}, \mathrm{Ha}, \mathrm{Hc}, \mathrm{He}, \mathrm{Hf}$ and $\mathrm{Hg}$ protons of $\mathrm{AC}$, respectively. Because of 1-4 interactions with $\mathrm{Hb}$ and He protons, the dublet-dublet peak seen more downfield at $8.69 \mathrm{ppm}$ was related to

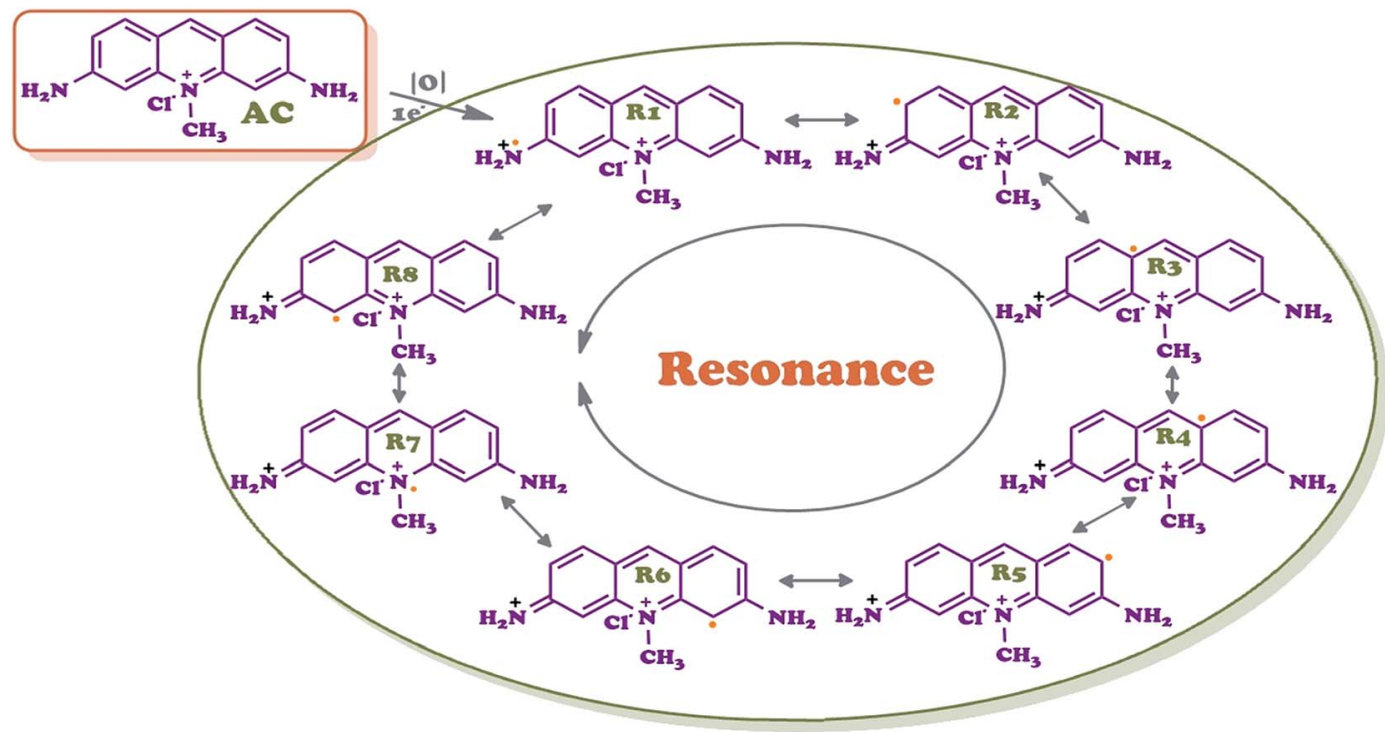

Scheme 2 Possible resonance and coupling modes of acriflavine (AC). 


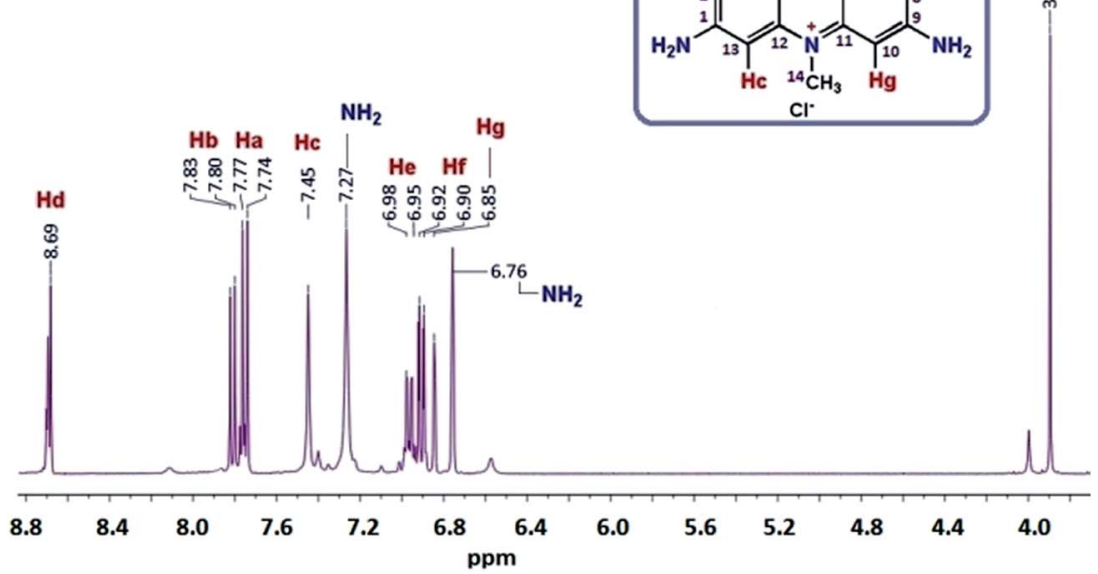

Fig. $1{ }^{1} \mathrm{H}$ NMR spectrum of acriflavine (AC).

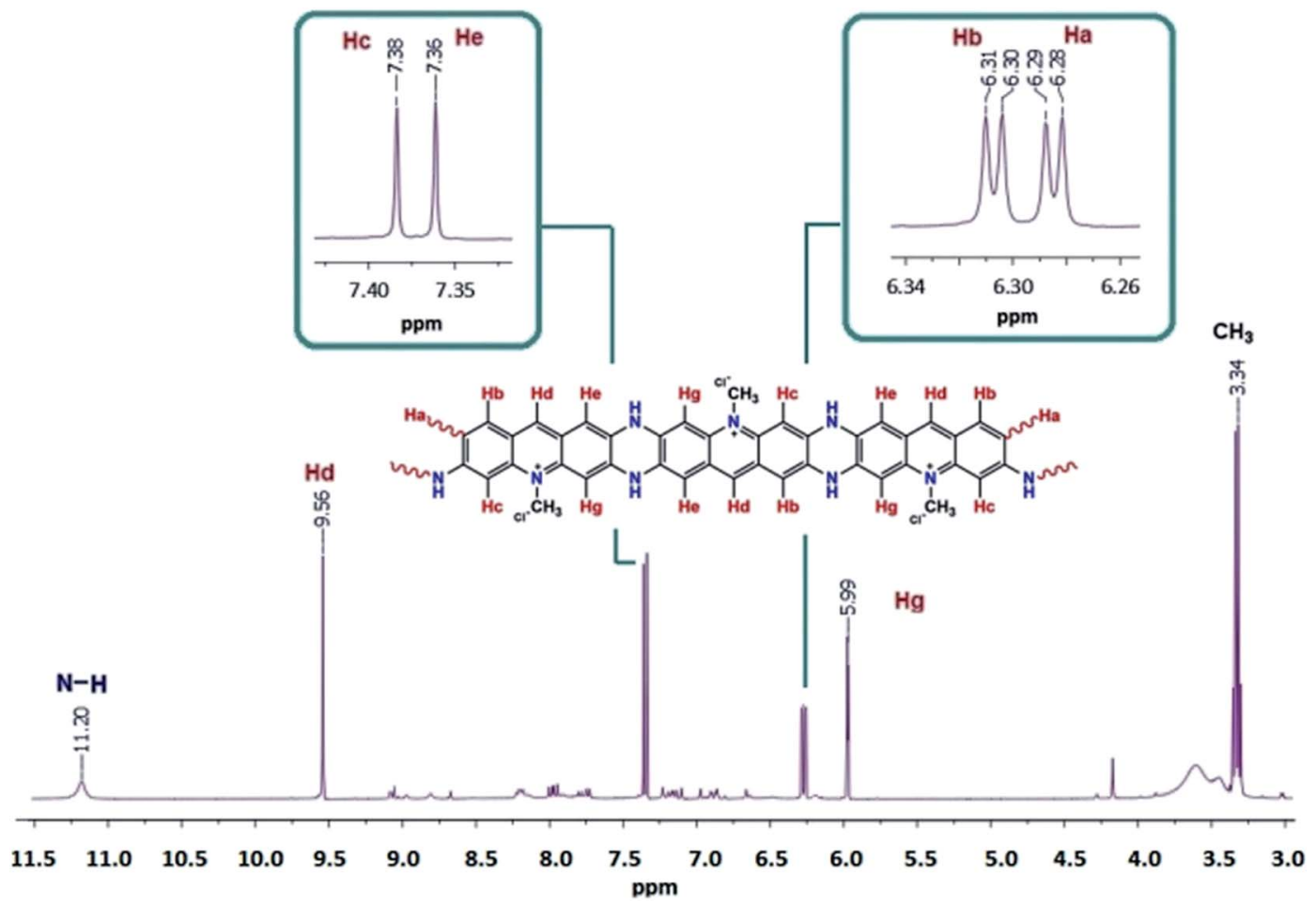

Fig. $2{ }^{1} \mathrm{H}$ NMR spectrum of $O A C$.

the Hd proton. The peaks for Ha protons were observed as terminal protons in the spectrum of OAC. The peak for the methylene $\left(-\mathrm{CH}_{3}\right)$ protons was observed as a singlet at $3.90 \mathrm{ppm}$. The signals of hydrogens in the phenylene unit shifted to lower fields after polymerization, which was significant for the $\pi$-conjugated polymers. ${ }^{43}$ The broad proton signals with respect to AC unit indicated that oligomer OAC consisted of repeating units with different chemical surroundings. The proton signals of $\mathrm{NH}_{2}$ group at 6.76 and 7.27 ppm almost disappeared and observed at $11.20 \mathrm{ppm}$ as a secondary amine after
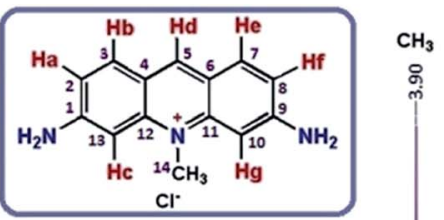

요 
shifting peaks for C1, C2, C8 and C9 downfield between 163.18 and $169.12 \mathrm{ppm}$. The peaks at 117.42, 120.49, 158.55 and 159.17 ppm indicated the presence of terminal C1, C9, C2 and C8, respectively. C10 and C13 peaks were observed at 116.92 and $116.89 \mathrm{ppm}$ for AC appeared at $124.71 \mathrm{ppm}$ in the spectrum of OAC the proposed structure of oligomer is confirmed according to the ${ }^{1} \mathrm{H}$ NMR and ${ }^{13} \mathrm{C}$ NMR spectral results in Fig. 2 and 3. The proposed structure for the oligomer was supported by UV-Vis and FT-IR analyses. Our claim for the polymerization of AC was that polymerization primarily took place via $\mathrm{C} 1$ and $\mathrm{C} 2$ phenylene units form both sides of acriflavine.

The molecular weight of OAC was determined using GPC chromatogram indicating that $M_{\mathrm{n}}$ and $M_{\mathrm{w}}$ weight were calculated as 4200 and $4950 \mathrm{Da}$, respectively, with a mono modal particle size distribution by RID detector, resulting in that OAC was oligomeric structured. OAC had a polydispersity index (PDI) value of 1.18. According to the average molecular weight value, the average constitutional units in OAC were nearly 19-22.

To research the crystal structures of AC and OAC, the powder XRD analysis was conducted. The crystallite sizes of the monomer and the oligomer are given in Table 1. The calculated $(D)$ values gave information about the types of crystal structure and the interlayer spacing $(d)$. The analyzed samples of AC and OAC were finely grounded and homogenized. Using the diffraction data, the mean crystallite sizes of the monomer and the oligomer, $D$, were determined according to the DebyeScherer equation $D=(0.9 \lambda) /(\beta \cos \theta)$, where $\lambda$ was X-ray wavelength (1.5406 $\AA$ ), $\theta$ was Bragg diffraction angle, and $\beta$ was the full width at half maximum of the diffraction peak. ${ }^{45,46}$ In view of the importance of knowing crystal sizes and interlayer spacings $(d)$ obtained from the angle at which the corresponding peak is diffracted in $\mathrm{AC}$ and OAC, it can be proposed the percent of the crystallinity of AC and OAC. The peak at $2 \theta=26.8^{\circ}$ for AC disappeared, substituted by a new weakened broad peak at around $2 \theta=27^{\circ}$ for OAC. A decrease in the percentage crystalline was observed from 33 to $19 \%$ for AC and OAC, respectively, due to the loss of peaks at $2 \theta$ value of $18.4^{\circ}$ and the decrease in peak intensities. Highly intense four diffraction peaks were observed at $2 \theta=32.8^{\circ}, 44.7^{\circ}, 65.1^{\circ}$ and $78.25^{\circ}$ and four less intense peaks observed at $2 \theta=18.4^{\circ}, 26.8^{\circ}$ and $47.6^{\circ}$ for the monomer AC. The four intense peaks were observed at $2 \theta=32.8^{\circ}, 44.7^{\circ}, 65.03^{\circ}$ and $78.24^{\circ}$ for the oligomer OAC. The peak corresponding to $\mathrm{AC}$ seen at $2 \theta=26.17^{\circ}$ became lower and broader in OAC, which revealed that the sample was partially crystallized. ${ }^{47}$ The low crystallinity could result from the long range ordering of the oligomer chains. ${ }^{48}$ Less intense peaks of OAC were attributed to the periodicity parallel to oligomer chains. A decrease in the crystallite size caused an increase in the width of the diffraction as peak broadening. On either side of the Bragg angle, the diffracted beam destructively interfered and resulted in a sharp peak.

\section{Optical and electrochemical properties}

The UV-vis spectra of AC and OAC are recorded using DMSO at room temperature and shown in Fig. 4. The peaks concerning $\pi \rightarrow \pi^{*}$ electronic transitions for the phenylene ring were

Table 1 XRD parameters of $A C$ and OAC

\begin{tabular}{llllll}
\hline & \multicolumn{2}{l}{ Peak pos. $\begin{array}{l}\beta \text { (B obs. } \\
{\left[{ }^{\circ} 2 \theta\right]}\end{array}$} & $\begin{array}{l}\text { Crystallite } \\
\left.\left[{ }^{\circ} 2 \theta\right]\right)\end{array}$ & $\cos \theta$-Spacing \\
Sompounds $[\mathrm{nm}]$ & {$[\AA]$}
\end{tabular}

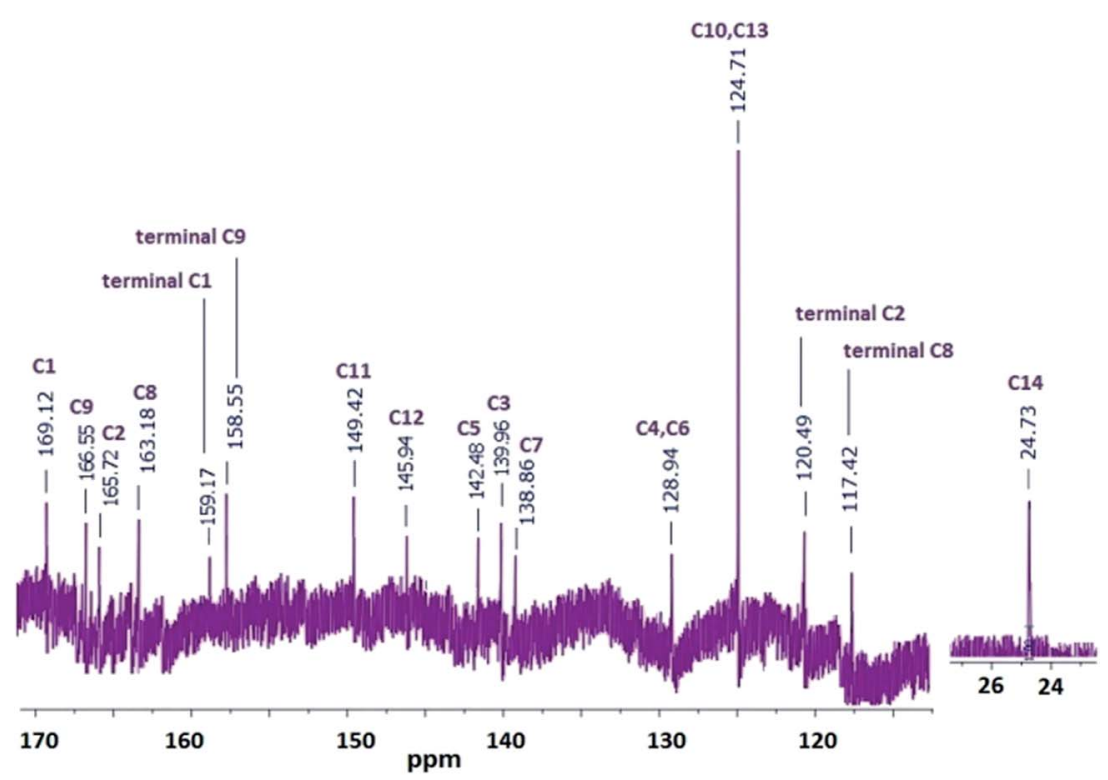

Fig. $3{ }^{13} \mathrm{C}$ NMR spectrum of OAC. 

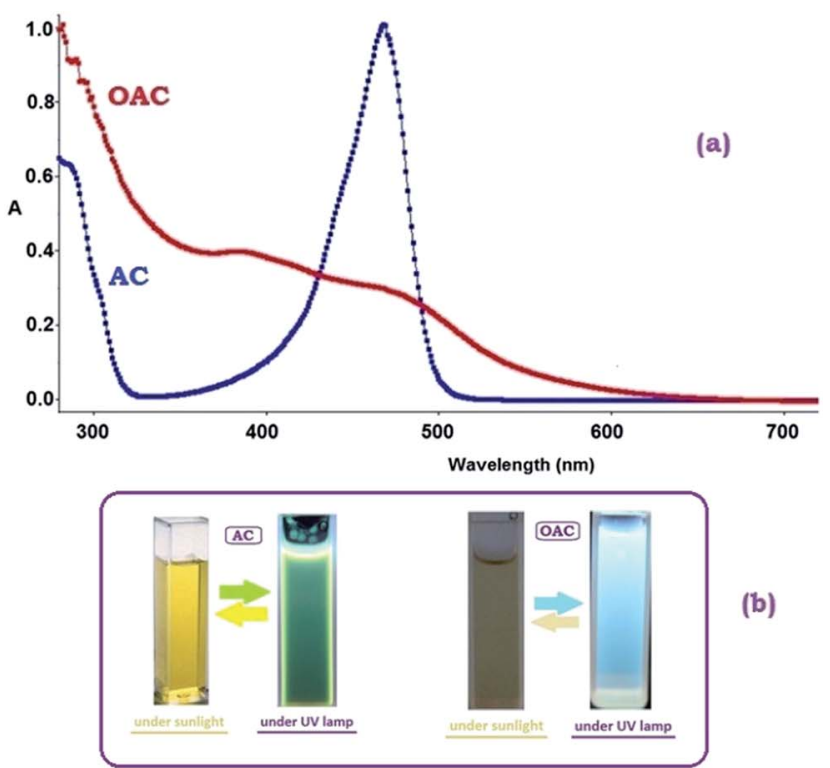

(b)

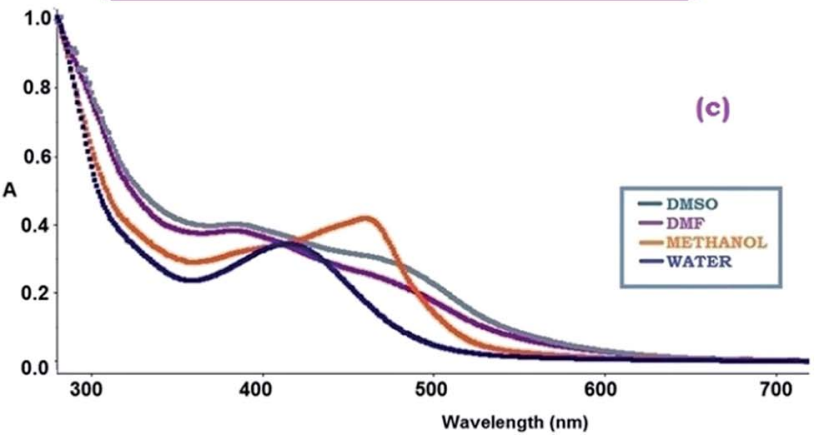

Fig. 4 Absorption spectra of (a) (AC) and (OAC) in DMSO, (b) the colors of $A C$ and $O A C$ under room light and UV light, (c) absorption spectra of $O A C$ in different solvents.

observed in the range of below $300 \mathrm{~nm} . \mathrm{n} \rightarrow \pi^{*}$ transition of imine bond for AC and OAC appeared at 468 and $473 \mathrm{~nm}$, respectively, due to the fact that as $\pi$-conjugated systems get larger, the energy gap for a $\mathrm{n} \rightarrow \pi *$ transition becomes narrow and the corresponding wavelength of light absorbed becomes longer. In comparison to the starting material (AC), it was possible to verify that the maximum peak at $475 \mathrm{~nm}$ for OAC is red-shifted with a broadened absorption. The observable band broadening for OAC in Fig. 4a was common for conductive polymers of a polyconjugated structure, indicating that polymerization was accomplished. It is well known that phenazine cycles have an optical absorption at a wavelength of 450$600 \mathrm{~nm} .{ }^{49}$ Phenazine cycles participated in the subsequent chain growth.

From an analysis of the absorption spectra, it is possible to evaluate the optical band gap energy. The optical band gap values $\left(E_{\mathrm{g}}\right)$ are obtained by using the following equation as in the literature and were given in Table 2.

$$
E_{\mathrm{g}}=1242 / \lambda_{\text {onset }}
$$

where $\lambda_{\text {onset }}$ is the onset wavelength which can be determined by intersection of two tangents on the absorption edges. $\lambda_{\text {onset }}$
Table 2 Electronic and optical structure parameters of AC and OAC

\begin{tabular}{lllll}
\hline Compounds & $\mathrm{HOMO}^{a}(\mathrm{eV})$ & $\mathrm{LUMO}^{b}(\mathrm{eV})$ & $E_{\mathrm{g}}^{\prime}{ }^{c}(\mathrm{eV})$ & $E_{\mathrm{g}}{ }^{d}(\mathrm{eV})$ \\
\hline AC & -5.45 & -2.83 & 2.62 & 2.46 \\
OAC & -5.79 & -3.11 & 2.43 & 2.20
\end{tabular}

${ }^{a}$ Highest occupied molecular orbital. ${ }^{b}$ Lowest unoccupied molecular orbital. ${ }^{c}$ Electrochemical band gap. ${ }^{d}$ Optical band gap.

also indicates the starting wavelength for the electronic transition. $^{50}$ The wavelengths $\lambda_{\text {onset }}$ obtained from the onset of the UV-Vis absorption band were found to be 505 and $562 \mathrm{~nm}$, and the $E_{\mathrm{g}}$ values were calculated as 2.46 and $2.20 \mathrm{eV}$ for $\mathrm{AC}$ and OAC, respectively, concluding that OAC possessed semiconductor property. The synthesized conjugated OAC had lower optical band gap value than that of AC. The overall absorption of OAC exhibited an absorption at $385 \mathrm{~nm}$ and tailed off to about $700 \mathrm{~nm}$ ascribed to the increase in the conjugated chain length of the oligomer, resulting in a decrease in the optical band gap between the energy levels of highest occupied molecular orbital $\left(E_{\text {Номо }}\right)$ and the lowest occupied molecular orbital $\left(E_{\text {LUMO }}\right)$. Depending on the foregoing results, the synthesized oligomer (OAC) is expected to have higher electrical conductivity owing to its lower band gap. Fig. 4b displayed visible color of AC and OAC under room light and UV light. The yellow solution of AC turned into green under UV-lamp. The pale brown color of OAC turned into blue when excited with the wavelength of $365 \mathrm{~nm}$.

The effect of solvent polarity on UV-vis spectra was also examined and shown in Fig. 4c. The effect of solvent polarity was clearly seen on the positions, intensities and shapes of the absorption bands of OAC. The spectral shifts in DMSO, DMF, methanol and water with different polarities mainly depends on the strength of the intermolecular hydrogen bonds between the $-\mathrm{NH}$ group of OAC and the -OH, carbonyl (CO) or sulfonyl (SO) functional groups of the solvent molecules. ${ }^{51,52}$ The maxima of the absorption curves appear to undergo blue shifts with increasing solvent polarity. As seen in Fig. $4 \mathrm{c}, \lambda_{\max }$ values were found to be 490, 459, 458 and 414 in DMF, DMSO, methanol and water, respectively. The free pair of electrons on nitrogen atom of OAC were lost via H-bonding leading to the hyposochromically (blue shift) shift of $\pi-\pi^{*}$ bands due to a decrease in conjugation and delocalization of the $\pi$-electrons when the solvent polarity increased. The shift to shorter wavelength was more enhanced in polar protic solvents like methanol and water than that in apolar protic solvents. The clarification could be based on that a blue shift induced by increasing the polarity of the solvent signified a decrease in the polar quinoid resonance forms. The benzene substituents in OAC are electron donors with unshared electron pairs that may partake in hydrogen bonds with the solvent. Blue shifts would be accounted for that the interaction with polar solvents contributes to the stability of the ground state more than it does to the excited state..$^{53}$

Therefore, OAC was expected to show a semiconductor behavior as result of oxidative polymerization. Additionally, the lowest optical band gap was expected to observe in DMF or DMSO due to their aprotic polar solvent property to prevent the 
formation of a hydrogen bond between OAC and the solvent, concurrent with an increase in conjugation and delocalization of the $\pi$-electrons.

The electrochemical properties and redox behavior of $\mathrm{AC}$ and its oligomer were studied using cyclic voltammograms (CVs) carried out in acetonitrile as the supporting electrolyte at room temperature under argon atmosphere are given in Fig. 5. Based on the correlations between the HOMO and LUMO energy levels and redox potentials, the value of the energy levels can be calculated using the onset values of the oxidation and reduction peaks. Making the correlation between redox process and the energy levels, it was possible to determine the electrochemical band gap energy $\left(E_{\mathrm{g}}^{\prime}\right)$ of the oligomer. The HOMOLUMO energy levels and electrochemical band gaps $\left(E_{\mathrm{g}}^{\prime}\right)$ were calculated using the oxidation $\left(E_{\mathrm{ox}}\right)$ and reduction peak potentials $\left(E_{\text {red }}\right)$ as shown in Table 2. The determination of HOMOLUMO energy levels were possible by using the empirical formulas: ${ }^{54}$

$$
\begin{aligned}
& E_{\mathrm{HOMO}}=-\left(4.39+E_{\mathrm{ox}}\right) \\
& E_{\mathrm{LUMO}}=-\left(4.39+E_{\mathrm{red}}\right) \\
& E_{\mathrm{g}}^{\prime}=E_{\mathrm{LUMO}}-E_{\mathrm{HOMO}}
\end{aligned}
$$

As displayed in Fig. 5, the oxidation of acriflavine initially produced the radical cation that reacted with another monomer molecule to produce oligo(acriflavine). Two oxidation peaks observed at 1.34 and $1.30 \mathrm{~V}$ can be attributed to the oxidation of free $\mathrm{NH}_{2}$ group of $\mathrm{AC}$ to form polaron structure $\left({ }^{\cdot+} \mathrm{NH}\right)$, and the oxidation of $-\mathrm{NH}_{2}$ group to form cation radical for OAC in the anodic region, respectively, which are not stable and undergo chemical reactions with parent molecule or dimerization reactions. The acriflavine unit is first oxidized by the formation of a radical cation which then, combines to form dimer and higher oligomers. ${ }^{55}$ The reduction peak potentials were concerned with the neutralization of the oxidized states of the oligomer.

The diagrams revealed the tendency of the HOMO elevation and on the contrary, the LUMO reduction through the oligomer formation (Table 2). Since the electrochemical band gap of OAC

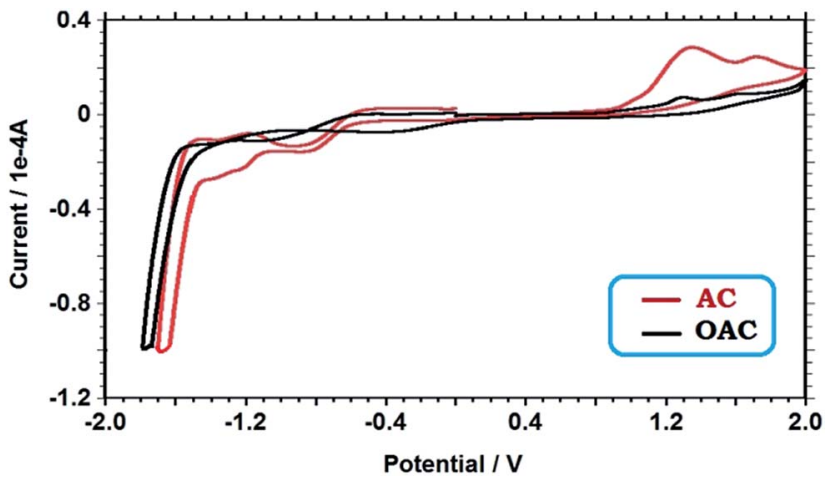

Fig. 5 Cyclic voltammograms of the monomer (AC) and its oligomer (OAC). was lower than that of $\mathrm{AC}$, the electrochemical band gap $\left(E_{\mathrm{g}}^{\prime}\right)$ values confirmed the optical band gap values $\left(E_{\mathrm{g}}\right)$.

\section{Fluorescence characteristics}

Since acriflavine has been used as color development reagent for spectrophotometric and fluorimetric determination, ${ }^{56,57}$ it was necessary to study the fluorescence properties of its polymerization product (OAC). The photoluminescence (PL) spectra of AC and OAC in different solvents were recorded as shown in Fig. 6.

Photoluminescence (PL) spectra of monomer (AC) could be recorded in only DMF and DMSO with a slit width of $3 \mathrm{~nm}$, because the emission exceeded 1000 a.u of PL intensity in water and methanol. The monomer was a green light emitter with an emission maximum at 517 and $497 \mathrm{~nm}$ in DMF and DMSO, respectively. The intensities in DMF and DMSO were observed as 659 and 151 a.u, respectively (Fig. 6a). On the other hand, the oligomer had a different property from the monomer with an extra emission of blue color when excited by UV radiation. Fig. $6 \mathrm{~b}$ gives information about the emission spectra of OAC in various solvents. As seen in Fig. 5b, the fluorescence intensity of OAC decreases with increasing the polarity of solvent. Maximum emission wavelength $\left(\lambda_{\max }\right)$ of OAC in DMSO, DMF,
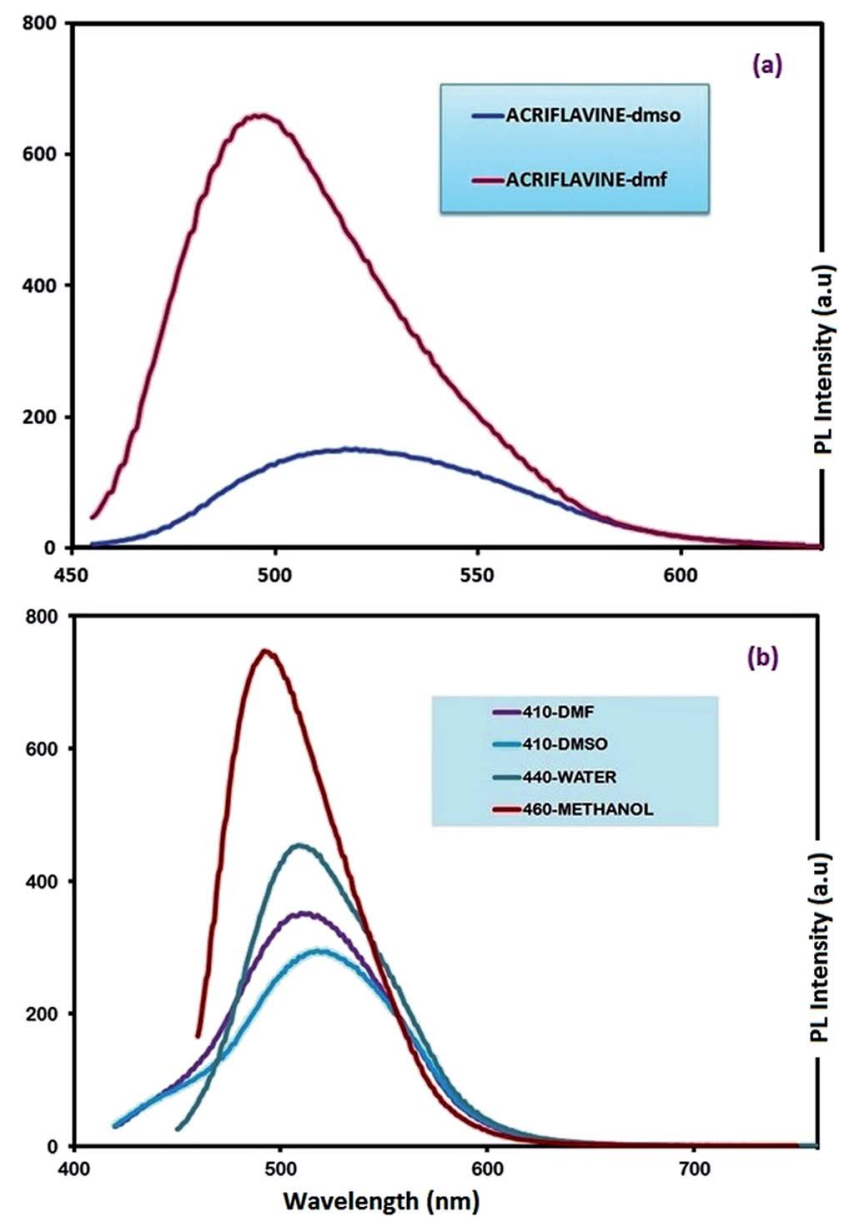

Fig. 6 Emission spectra of $A C$ (a) and OAC (b) solutions in selected solvents. Slit width: $3 \mathrm{~nm}$ and conc.: $10 \mathrm{mg} \mathrm{L}^{-1}$ in all measurements. 
$\mathrm{H}_{2} \mathrm{O}$ and $\mathrm{MeOH}$ appeared at 437, 440, 441 and $441 \mathrm{~nm}$ with the appearance of a blue color emission and 521, 518, 510 and $521 \mathrm{~nm}$ with the emission of yellow color when excited by UV and visible light, respectively. The obtained results revealed that the spectrum was affected by polarity depending on proticaprotic nature of solvent.

In $\mathrm{MeOH}$ and $\mathrm{H}_{2} \mathrm{O}$ protic solvents, OAC emitted bicolored fluorescent light with blue and green colors when excited at 380 and $460 \mathrm{~nm}$, respectively as seen in Fig. 7. In DMF and DMSO aprotic solvents, the excitation of OAC with 380 and $460 \mathrm{~nm}$ resulted in the blue and green fluorescence light at around 440 and $520 \mathrm{~nm}$, respectively, as seen in Fig. 8. The intensities of bicolored fluorescent light emission were 300 and 800 with the excitation wavelengths at 380 and $460 \mathrm{~nm}$, respectively. The behavior of bicolor emission when excited at different wavelengths can be explained in a way that polymers have a broad chain length distribution, and the longer conjugated chains have lower energy gaps with an emission light at longer wavelengths. Therefore, the wavelength of fluorescent emission increased as the wavelength of the excitation source increased. Quantum yield (QY) is another important contribution to PL characteristics. The oligomer OAC has the emission QY of 6\% in DMSO and 3\% in DMF for green PL emission.

To observe the multicolor emission with change of excitation wavelength, confocal microscope analysis was also performed in Fig. 9. A certain amount of OAC solution was dropped on a glass sheet and dried. The emission colors of blue and green colors were separately obtained by using confocal microscope with the excitation wavelengths of 360 and $470 \mathrm{~nm}$ agreed with
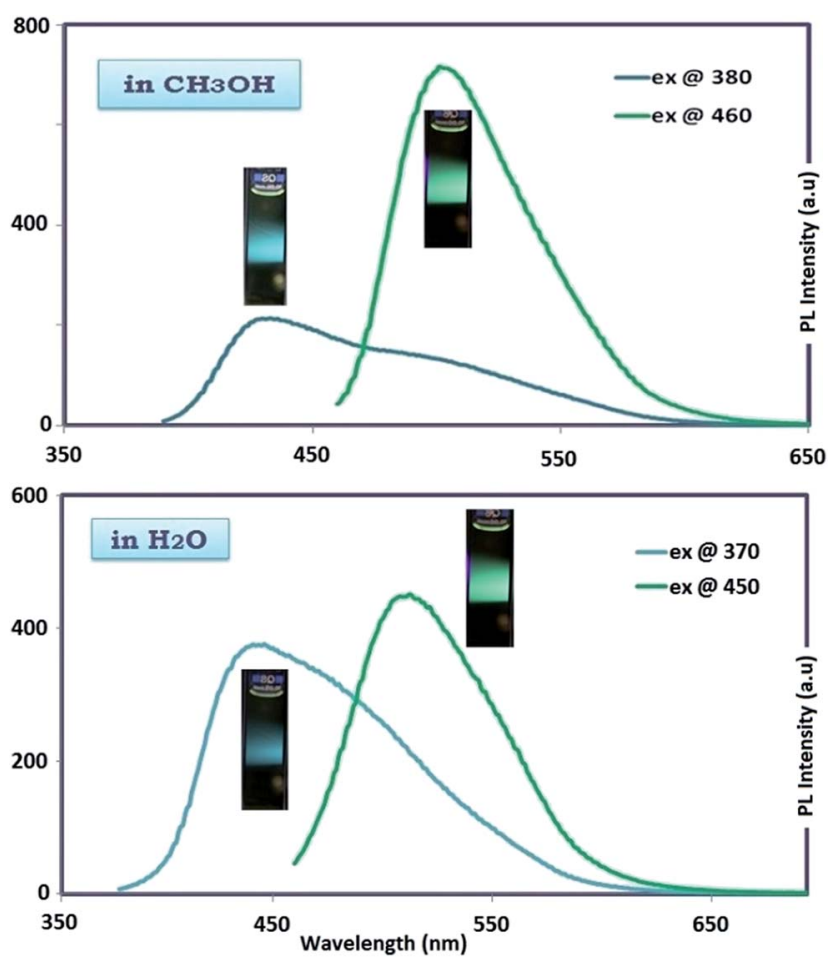

Fig. 7 Photographs and the corresponding of maximum emission spectra of $\mathrm{OAC}$ solution in $\mathrm{CH}_{3} \mathrm{OH}$ and $\mathrm{H}_{2} \mathrm{O}$. Slit width: $3 \mathrm{~nm}$ and conc.: $10 \mathrm{mg} \mathrm{L}^{-1}$ in all measurements. the PL ones very well. OAC displayed bicolor emission behavior in all selected polar solvents. OAC showed nearly similar emission characteristics under the same excitation wavelength in selected polar solvents such as DMF, DMSO, $\mathrm{MeOH}$ and water.

Based on foregoing results, OAC can be a very promising candidate for materials in light-emitting diodes due to their bicolor (blue and green) light-emitting property as fluorescent water soluble conjugated oligomer.

\section{Thermal properties}

The thermal degradation curves (TGA-DTG) for the synthesized oligomer AC and OAC at heating rates of $10{ }^{\circ} \mathrm{C}$ from ambient temperature to $1000{ }^{\circ} \mathrm{C}$ under nitrogen atmosphere are depicted
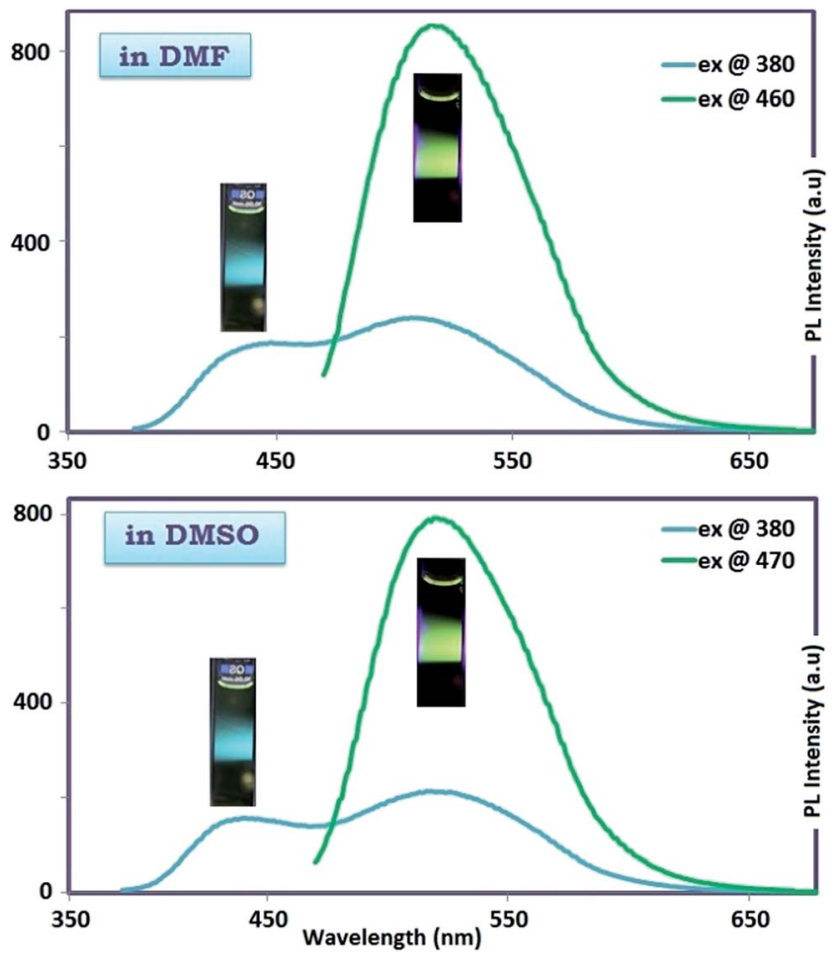

Fig. 8 Photographs and the corresponding of maximum emission spectra of OAC solution in DMF and DMSO. Slit width: $3 \mathrm{~nm}$ and conc.: $10 \mathrm{mg} \mathrm{L}^{-1}$ in all measurements.
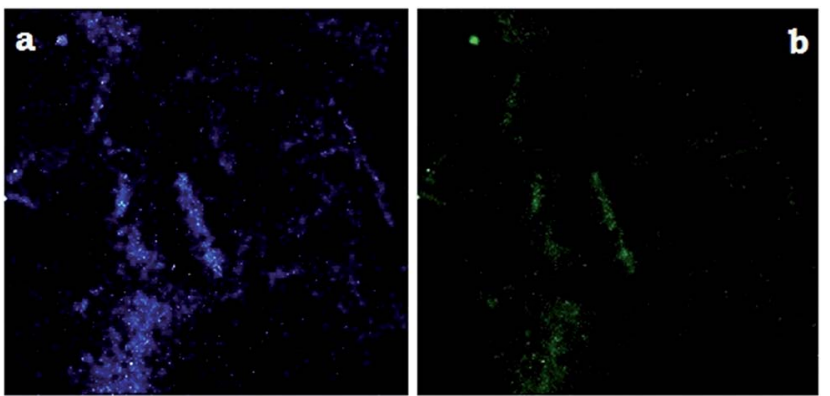

Fig. 9 Confocal microscope images of OAC. The excitation wavelengths were 380 (a), and 470 (b), respectively. 


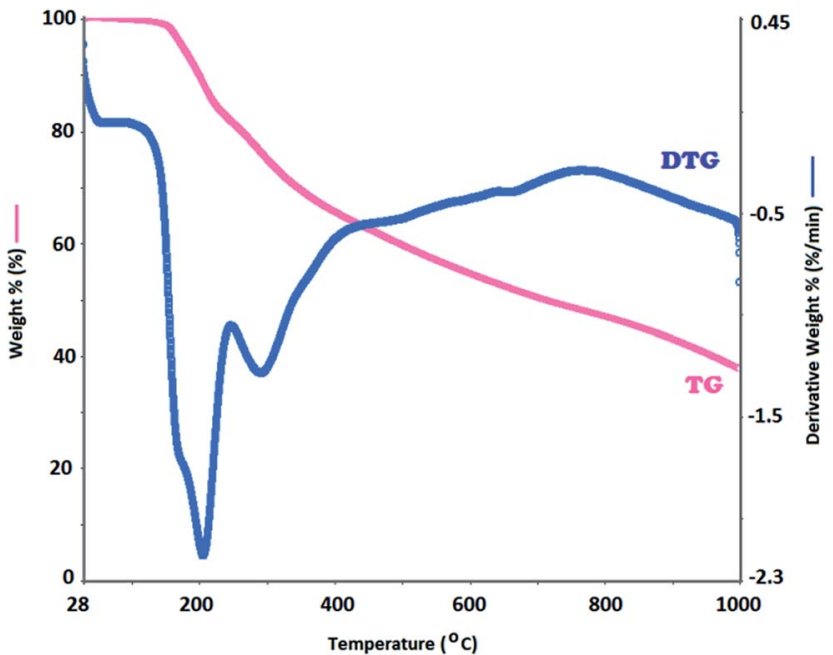

Fig. $10 \mathrm{TG} / \mathrm{DTG}$ profiles for $\mathrm{OAC}$ at $10{ }^{\circ} \mathrm{C}$ heating rate in nitrogen atmosphere.

in Fig. 10. TG-DTG analyses reveal that thermal degradation of $\mathrm{AC}$ and $\mathrm{OAC}$ happened in two stages. It was clearly seen in Fig. 10 that $5-7 \%$ weight loss assigned to the removal of the adsorption water for AC and OAC was observed around 50-120 ${ }^{\circ} \mathrm{C} .{ }^{58,59}$ As stressed in Table 3, despite the high thermal stability of the monomer (AC) the oligomer (OAC) showed low thermal resistance, because initial degradation temperatures $\left(T_{\mathrm{on}}\right)$ of $\mathrm{AC}$ and OAC were obtained to be 290 and $160{ }^{\circ} \mathrm{C}$, respectively. The temperatures corresponding to $20 \%\left(T_{20}\right)$ weight losses were calculated as 373 and $266{ }^{\circ} \mathrm{C}$, and the temperatures corresponding to $50 \%\left(T_{50}\right)$ weight losses were figured out as 628 and $719{ }^{\circ} \mathrm{C}$ for $\mathrm{AC}$ and $\mathrm{OAC}$, respectively. The maximum rate of weight loss $\left(T_{\max }\right)$ values obtained from the derivative thermogravimetry (DTG) curves were found to be 333 and $430{ }^{\circ} \mathrm{C}$ for $\mathrm{AC}$, and 206 and $292{ }^{\circ} \mathrm{C}$ for OAC, indicating that the thermal decomposition took place in two stages. The glass transition temperature $\left(T_{\mathrm{g}}\right)$ of OAC studied by differential scanning calorimeter (DSC) technique was found to be $139{ }^{\circ} \mathrm{C}$. In addition, the char\% amounts of AC and OAC at $1000{ }^{\circ} \mathrm{C}$ were obtained as $49.7 \%$ and $37.7 \%$, respectively. Based on foregoing thermal analysis data, it can be said that the synthesized oligomer is not thermally stable.

Table 3 Thermal degradation values of the synthesized compounds

\begin{tabular}{lll}
\hline Compounds/thermal data & AC & OAC \\
\hline$T_{\text {on }}{ }^{a}$ & 290 & 160 \\
$T_{\max }{ }^{b}$ & 333,430 & 206 \\
$20 \%$ weight loss & 373 & 266 \\
$50 \%$ weight loss & 628 & 719 \\
$\%$ char at $1000{ }^{\circ} \mathrm{C}$ & 49.7 & 37.7 \\
DTA $($ exo/endo) & $-/-$ & $-/-$ \\
DSC $\left[T_{\mathrm{g}}{ }^{c}\left({ }^{\circ} \mathrm{C}\right) / \Delta C_{\mathrm{p}}{ }^{d}\left(\mathrm{~J} \mathrm{~g}^{-1} \mathrm{~K}^{-1}\right)\right]$ & $-/-$ & $139 / 0.821$
\end{tabular}

${ }^{a}$ The onset temperature. ${ }^{b}$ Maximum weight loss temperature. ${ }^{c}$ Glass transition temperature. ${ }^{d}$ Change of specific heat during glass transition.

\section{Photovoltaic properties}

The photovoltaic power conversion efficiency of a solar cell $(\eta)$ is described as the ratio of generated electricity from the solar cell to incoming light energy. The efficiency of a solar cell is determined as the fraction of incident power which is converted to electricity and is defined as:

$$
\eta=\frac{I_{\mathrm{sc}} \times V_{\mathrm{oc}} \times \mathrm{FF}}{P_{\text {light }}}
$$

where $V_{\mathrm{oc}}$ is the open circuit voltage, $I_{\mathrm{sc}}$ is the short circuit current, and FF is the fill factor.

$$
\mathrm{FF}=\frac{I_{\mathrm{mp}} \times V_{\mathrm{mp}}}{I_{\mathrm{sc}} \times V_{\mathrm{oc}}}
$$

where $I_{\mathrm{mp}}$ and $V_{\mathrm{mp}}$ are the current and voltage at the maximum power point.

The characteristic intersections with abscissa and ordinate are the open circuit voltage $\left(V_{\mathrm{oc}}\right)$ and the short circuit current $\left(I_{\mathrm{sc}}\right)$, respectively, as seen in Fig. 11. The largest power output $\left(P_{\max }\right)$ is determined using the point at which the product of voltage and current has maximum value. Division of $P_{\max }$ by the product of $I_{\mathrm{sc}}$ and $V_{\mathrm{oc}}$ yields the fill factor FF. We have achieved 0.027 as \% $\eta$ under AM 1.5 irradiation $\left(100 \mathrm{~mW} \mathrm{~cm}^{-2}\right)$ with a dye-sensitized solar cells based on OAC, exhibiting a short circuit photocurrent density $J_{\mathrm{sc}}$ of $0.14 \mathrm{~mA} \mathrm{~cm}{ }^{-2}$, open circuit voltage $V_{\text {oc }}$ of $0.37 \mathrm{~V}$, and the fill factor $\mathrm{FF}$ of 0.50 . It can be concluded that OAC is moderately effective as an organic-dye photosensitizer for use in dye-sensitized solar cells. The reason regarding to performance of the organic photovoltaics depends on the following factors. (1) Broad and strong absorption in visible and near IR region to match with solar spectrum (2) suitable LUMO energy level of acceptor and HOMO energy level of donor to maintain $V_{\text {oc }}$ (3) optimum morphology donor-acceptor with nanoscale phase separation within active layer which influences $J_{\mathrm{sc}}, V_{\mathrm{oc}}$ and FF. ${ }^{60}$

\section{Morphological and electrical properties}

The morphology of OAC has been characterized by scanning electron microscopy (SEM). SEM views at different amplifications are shown in Fig. 12. According to the SEM images, the

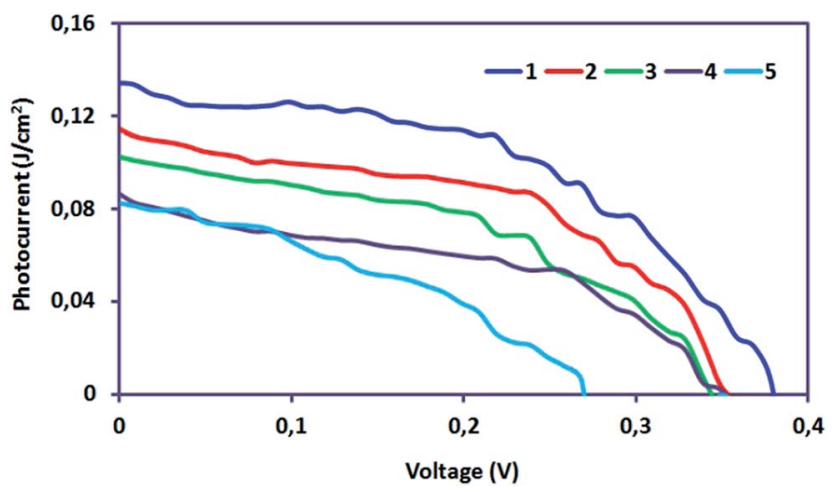

Fig. $11 \mathrm{~J}-V$ curves under different light intensities $\left(1: 100 \mathrm{~mW} \mathrm{~cm}^{-2}\right.$; 2: $80 \mathrm{~mW} \mathrm{~cm}^{-2} ; 3: 60 \mathrm{~mW} \mathrm{~cm}^{-2} ; 4: 40 \mathrm{~mW} \mathrm{~cm}^{-2} ; 5: 20 \mathrm{~mW} \mathrm{~cm}^{-2}$ ). 

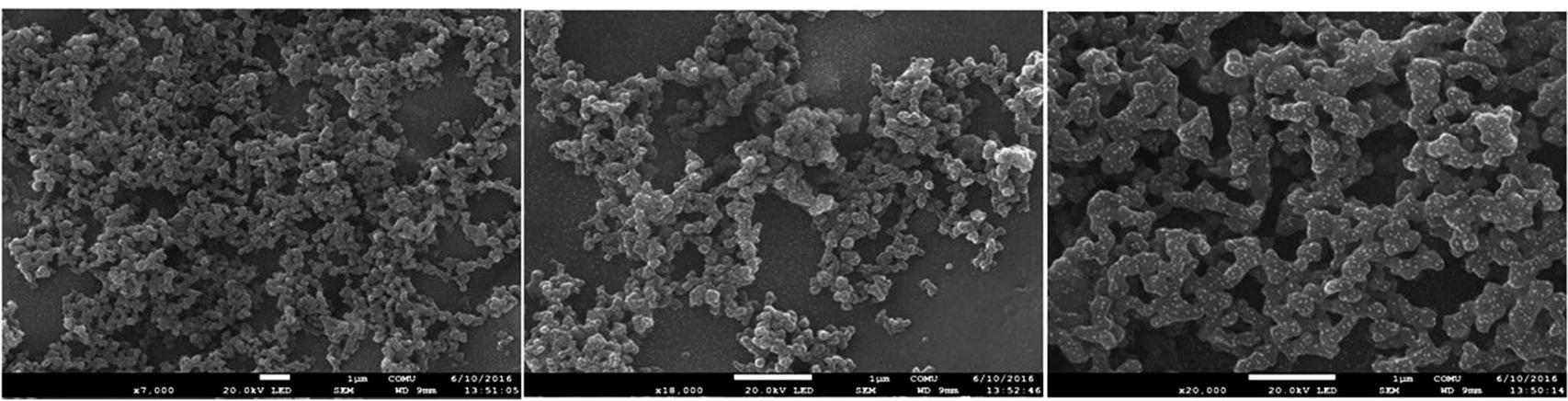

Fig. 12 SEM views of electrospinning results.

polymer surface morphology was smooth without any noticeable pinholes or cracks within the conventional SEM resolution seen in Fig. 12. The size of the OAC particles can be as large as several micrometers. The molecular structure of OAC was relatively flat and regular which meant that the polymerization took place over forming one pyrazine ring as a result of an intramolecular cyclization, leading to the ladder segments and phenazine structures along oligomer chain of OAC.

By the exposure of the pellet to iodine vapor in a dessicator at room temperature, the conductivity of iodine doped oligomer depending on time could be followed. ${ }^{61}$ The virgin electrical conductivity of OAC was measured to be $2.35 \times 10^{-9} \mathrm{~S} \mathrm{~cm}^{-1}$. Upon doping with iodine at room temperature in a vacuum desiccator, its conductivity increased to $5.90 \times 10^{-9} \mathrm{~S} \mathrm{~cm}^{-1}$ in $6 \mathrm{~h}$ and increased by about two orders of magnitude reached to $1.86 \times 10^{-7} \mathrm{~S} \mathrm{~cm}^{-1}$ in 24 hours. The values were $3.1 \times 10^{-7}$, $3.96 \times 10^{-7}, 7 \times 10^{-7}, 9.94 \times 10^{-7}$ and $1.08 \times 10^{-6} \mathrm{~S} \mathrm{~cm}^{-1}$ by doping in 48, 72, 96 and 120 hours, respectively. Since nitrogen is an electronegative element, iodine doped oligomer generally occurs by coordination of iodine with nitrogen atoms in the oligomer structure. The results revealed that the electrical conductivity of iodine-doped pellet of OAC increased about three orders of magnitude and reached to about $10^{-6} \mathrm{~S} \mathrm{~cm}^{-1}$ value in 120 hours. The conductivity first increased with doping time, then tend to level-off. As emphasized, there is an opposite correlation between the values of HOMO-LUMO band gap and the conductivity. A lower band gap makes the electronic transition easier with obtaining higher conductivity values. Consequently, it can be said that OAC is semi-conducting structured.

\section{Conclusion}

The oxidation of acriflavine with hydrogen peroxide resulted in the formation of an oxidation product with the molar mass of several thousands, leading to having an oligomeric nature rather than an oligomeric structure. By a combined application of spectroscopic and spectroelectrochemical techniques, the structural details of the formation of phenazine-like units has been studied in detail. From the application point of view, the combined effects of inclusion of acriflavine and polymerization azomethine-based compounds improve the photophysical, thermal and morphological properties. Fluorescent spectral studies indicated that OAC was a good candidate for blue- and green-light emitter. Furthermore, OAC manifested thermal stability and smooth homogeneous surfaces. With these attractive properties, the synthesized oligomer has many potential applications in various fields. Thus, it can be inferred that the introduction of acriflavine to the procedure in oligomer formation would significantly improve the photophysical and thermal properties. These results provide important structureactivity relationship that can be used to predict the morphological and electro-optical properties of conjugated oligomer.

Conjugated organic dyes, which have OAC moiety as the electron donor showed moderate performance as a photosensitizer in dye-sensitized solar cells. A maximum solar-energy-toelectricity conversion efficiency $(\eta)$ of $0.027 \%$ under AM 1.5 irradiation $\left(100 \mathrm{~mW} \mathrm{~cm}^{-2}\right)$ with a dye-sensitized solar cell. The crystalline nature and bicolored emission property of oligo(acriflavine) provide potential applications in bicolored fluorescent labeling in bioscience and the fabrication of nano-devices. The study may be carried forward by designing a better structure of OAC with light absorbing low band gap donor-acceptor morphology in nanoscale for better photon harvesting and thereby may increase the photocurrent in solar cell.

\section{Acknowledgements}

The authors thank Çanakkale Onsekiz Mart University scientific research project commission for support with the project number (Project Nu.: FBA-2016-710).

\section{References}

1 S. P. Economopoulos, A. K. Andreopoulou, V. G. Gregoriou and J. K. Kallitsis, Chem. Mater., 2005, 17, 1063-1071.

2 W. Y. Huang, H. Yun, H. S. Lin, T. K. Kwei and Y. Okamoto, Macromolecules, 1999, 32, 8089-8093.

3 A. Kimyonok, X. Y. Wang and M. Weck, J. Macromol. Sci., Polym. Rev., 2006, 46, 47-77.

4 A. S. Anselmo, L. J. Lindgren, J. Rysz, A. Bernasik, A. Budkowski, M. R. Andersson, K. Svensson, J. van Stam and E. Moons, Chem. Mater., 2011, 23, 2295-2302.

5 R. Wilson and A. P. F. Turner, Biosens. Bioelectron., 1992, 7, 165-185. 
6 S. Hellstrom, L. J. Lindgren, Y. Zhou, F. L. Zhang, O. Inganas and M. R. Andersson, Polym. Chem., 2010, 1, 1272-1280.

7 M. K. Ram, N. S. Sundaresan and B. D. Malhotra, J. Mater. Sci. Lett., 1994, 13, 1490-1493.

8 W. H. Meyer, H. Kiess, B. Binggeli, E. Meier and G. Harbeke, Synth. Met., 1985, 10, 255-259.

9 Handbook of organic conductive materials and polymers, ed. $\mathrm{H}$. S. Nalwa, Wiley, New York, 1997.

10 V. Saxena and B. D. Malhotra, Curr. Appl. Phys., 2003, 3, 293305.

11 A. Rizzo, N. Solin, L. J. Lindgren, M. R. Andersson and O. Inganas, Nano Lett., 2010, 10, 2225-2230.

12 S. Kobayashi and A. Makino, Chem. Rev., 2009, 109, 52885353.

13 W. Liu, S. Bian, L. Li, L. Samuelson, J. Kumar and S. Tripathy, Chem. Mater., 2000, 12, 1577-1584.

14 K. Hara, K. Sayama, Y. Ohga, A. Shinpo, S. Suga and H. Arakawa, Chem. Commun., 2001, 569-570.

15 K. Hara, M. Kurashige, Y. Dan-oh, C. Kasada, A. Shinpo, S. Suga, K. Sayama and H. Arakawa, New J. Chem., 2003, 27, 783-785.

16 T. Horiuchi, H. Miura and S. Uchida, Chem. Commun., 2003, 21, 3036-3037.

17 T. Horiuchi, H. Miura and S. Uchida, J. Photochem. Photobiol., A, 2004, 164, 29-32.

18 A. Ehret, L. Stuhl and M. T. Spitler, J. Phys. Chem. B, 2001, 105, 9960-9965.

19 Q. H. Yao, F. S. Meng, F. Y. Li, H. Tian and C. H. Huang, J. Mater. Chem., 2003, 13, 1048-1053.

20 Z. S. Wang, F. Y. Li and C. H. Huang, Chem. Commun., 2000, 20, 2063-2064.

21 H. H. Lu, Y. S. Ma, N. J. Yang, G. H. Lin, Y. C. Wu and S. A. Chen, J. Am. Chem. Soc., 2011, 133, 9634-9637.

22 C. V. Hoven, A. Garcia, G. C. Bazan and N. Thuc-Quyen, Adv. Mater., 2008, 20, 3793-3810.

23 X. Lu, Q. Fan, G. Zhang, K. Pu and W. Huang, Sci. China: Chem., 2010, 53, 1122-1127.

24 K. Zhang, X. Guan, F. Huang and Y. Cao, Acta Chim. Sin., 2012, 70, 2489-2495.

25 F. Huang, H. B. Wu and Y. Cao, Chem. Soc. Rev., 2010, 39, 2500-2521.

26 B. Liu, W. L. Yu, Y. H. Lai and W. Huang, Macromolecules, 2002, 35, 4975-4982.

27 M. Onoda, K. Tada, M. Ozaki and K. Yoshino, Thin Solid Films, 2000, 363, 9-12.

28 R. E. Bauer, V. Enkelmann, U. M. Wiesler, A. J. Berresheim and K. Müllen, Chem.-Eur. J., 2002, 8, 3858-3864.

29 M. J. Winokur and B. R. Mattes, Macromolecules, 1998, 31, 8183-8191.

30 Z. Mo, K. B. Lee, Y. B. Moon, M. Kobayashi, A. J. Heeger and F. Wudl, Macromolecules, 1985, 18, 1972-1977.

31 Y. F. Zhou, M. Eck and M. Kruger, Energy Environ. Sci., 2010, 3, 1851-1864.

32 Y. Li, H. Kuwabara, Y. K. Gong, Y. Takaki and K. Nakashima, J. Photochem. Photobiol., B, 2003, 70, 171-176.
33 S. H. Choi, J. Y. Cho, Y. S. Chung, E. K. Hong, Y. B. Han and S. G. Kim, Int. J. Immunopharmacol., 2000, 22, 775-787.

34 T. I. Grishaeva and A. I. Zakharov, Zh. Anal. Khim., 1990, 45, 1333-1337.

35 A. T. R. Williams, S. A. Winfield and J. N. Miller, Analyst, 1983, 108, 1067-1071.

36 J. R. Lakowicz, Principles of fluorescence spectroscopy, Kluwer Academic/Plenum Publishers, New York, 2nd edn, 1999.

37 R. Cervini, X. C. Li, G. W. C. Spencer, A. B. Holmes, S. C. Moratti and R. H. Friend, Synth. Met., 1997, 84, 359-360.

38 H. Hoppe and N. S. Sariciftci, J. Mater. Chem., 2004, 19, 19241945.

39 G. Ćirić-Marjanović, M. Trchová and J. Stejskal, Int. J. Quantum Chem., 2008, 108, 318-333.

40 G. Ćirić-Marjanović, N. V. Blinova, M. Trchová and J. Stejskal, J. Phys. Chem. B, 2007, 111, 2188-2199.

41 M. B. Mitchell, G. R. Smith and W. A. Guillory, J. Chem. Phys., 1981, 75, 44-48.

42 K. Chiba, T. Ohsaka, Y. Ohnuki and N. Oyama, J. Electroanal. Chem., 1987, 219, 117-124.

43 A. Bilici, F. Dogan, M. Yıldırım and İ. Kaya, React. Funct. Polym., 2011, 71, 675-683.

44 A. Hathoot, M. Abdel-Kader and M. Abdel-Azzem, Int. J. Electrochem. Sci., 2009, 4, 208-222.

45 B. P. Baranwal, T. Fatma and A. Varna, J. Mol. Struct., 2009, 920, 472-477.

46 M. A. Short and P. L. Walker, Carbon, 1963, 1, 3-9.

47 J. Han, G. P. Song and R. Guo, Eur. Polym. J., 2007, 43, 42294235.

48 X. Lu, H. Mao, D. Chao, X. Zhao, W. Zhang and Y. Wei, Mater. Lett., 2007, 61, 1400-1403.

49 D. He, Y. Wu and B. Q. Xu, Eur. Polym. J., 2007, 43, 37033709.

50 K. Colladet, M. Nicolas, I. Goris, I. Lutsen and D. Vanderzande, Thin Solid Films, 2004, 451, 7-11.

51 A. V. Kulinich, N. A. Derevyanko and A. A. Ishchenko, Russ. J. Gen. Chem., 2006, 76, 1441-1457.

52 B. W. Domagalska, K. A. Wilk and R. Zielinski, J. Photochem. Photobiol., A, 2006, 184, 193-203.

53 H. E. Ungnada, J. Am. Chem. Soc., 1953, 75, 432-434.

54 W. Liu, S. Lee, S. Yang, S. Bian, L. Lia, L. A. Samuelson, J. Kumar and S. K. Tripathy, J. Macromol. Sci., Part A: Pure Appl. Chem., 2001, 38, 1355-1370.

55 E. T. Seo, R. F. Nelson, J. M. Fritsh, L. S. Marcoux, D. W. Leedy and N. Adams, J. Am. Chem. Soc., 1966, 88, 3498-3503.

56 R. Segarra Guerrero, C. Gomez Benito and J. Martinez Calatayud, Talanta, 1996, 43, 239-246.

57 J. M. Calatayud, J. V. G. Mateo and V. David, Analyst, 1998, 123, 429-434.

58 M. Yıldırım and I. Kaya, Synth. Met., 2012, 162, 436-443.

59 R. Solmaz and G. Kardas, Prog. Org. Coat., 2009, 64, 81-88.

60 N. B. Kolhe, S. Shinde, B. Saibal and S. K. Asha, Organic Photonics and Photovoltaics, 2015, 3, 71-100.

61 F. R. Diaz, J. Moreno, L. H. Tagle, G. A. East and D. Radic, Synth. Met., 1999, 100, 187-193. 